\title{
Group Testing As A Pedagogical Technique To Enhance Learning In Difficult Subjects
}

\author{
Marla G. Scafe, Walsh College, USA
}

\begin{abstract}
The purpose of this study was to evaluate the effectiveness of group testing as a pedagogical technique to enhance learning in a difficult subject such as statistics. Individual test scores were compared to their group test scores for the same, identical test. A t test was used to compare the scores for 157 randomly selected MBA students enrolled in a graduate level quantitative research methods course. Results of the $t$ test were significant $(t=-14.807, p=.000)$ illustrating that individual scores were significantly lower than the group scores.
\end{abstract}

Keywords: group testing; pedagogical technique; adult learners; difficult subjects

\section{INTRODUCTION}

$\mathrm{n}$ today's business environment, one must have strong interpersonal and group communication skills in
order to survive and retain one's position. Quality circles and cross-functional teams was the focus on research in the 1980's and their effectiveness in the workplace has not diminished. In fact, they are even more important in the workplace today as many employees face possible outsourcing, job elimination and unemployment. Knowing how to get along in group situations, tapping the knowledge and resources of others is no longer a luxury, but instead, is a vital skill in the workplace (Humphreys, Greenin, and McIIveen, 1997).

Walsh College of Accountancy and Business Administration teaches adult learners who work full time and complete their college degrees part time primarily in the evenings and on weekends. The mean age of a Walsh College undergraduate student is 28 years old and the mean age of a typical Walsh College graduate student is 38 years old. It has been Walsh College's philosophy since its accreditation as a degree granting institution to include group work as part of almost every class a business student takes at this institution. When work teams became popular in the 1980's, Walsh College reinforced its commitment to offer real world experiences in the classroom through group case studies and the like. In the early 1990's, Walsh College even adapted a group work policy that its faculty drafted and published on course syllabi. One would expect group work in management classes, especially courses like Organizational Behavior where group concepts are taught. What makes this paper unique is the research that shows how group work in a subject area that is usually perceived as challenging to the adult learner, such as Quantitative Research Methods and Statistics, can help the student master difficult concepts. This paper describes the process used to incorporate group work teams in an MBA Quantitative Research Methods and Statistics class. It illustrates how groups help adult learners master this difficult and, often times, intimidating class.

\section{LITERATURE REVIEW}

Research on the effectiveness of groups in classes, like most research, has conflicting results (Wilkenson, 2006; Muller, 1989; Huff, Cooper and Jones, 2002; Michaelsen and Black, 1994). There is much debate on whether or not groups really help students learn. Students who have experienced team projects in their business classes have been heard describing their experiences as being either good, mediocre, bad and even ugly. Anderson (2005) used computer-based group simulations in his business courses and found that a student's affect regarding the simulation game was influences by the team's cohesion independence. Student performance was influenced by team heterogeneity, opportunistic practices, and hypothesis driven thinking. 
Michaelsen's decades of research focused on various aspects of learning teams and how to effectively assess whether or not learning was taking plan at the team level (Michaelsen and Black, 1994; Michaelsen, Fink and Knight, 1997; Michaelsen, 1997, 98, and 99). In an article entitled, "Making Learning Groups Effective," Michaelsen and Razook (1999) outlined key ways to make groups effective such as engaging groups in contactfocused, give-and-take discussions and making groups accountable for linked and mutually reinforcing assignments.

Huff, Cooper and Jones (2002) developed a model of the determinants and consequences of creating a climate of trust within student group projects. The model specifies the attributes and behavior students consider when judging the trustworthiness of their fellow group members. Their article discusses the tools and activities that can be used to help facilitate group trust to heighten the group experience.

A longitudinal study was conducted by Watson, Michaelsen and Sharp (1991) to examine the extent to which member competence and increased experience working in a group would affect group problem solving skills. Results clearly showed that group decision making, even in difficult and ambiguous situations, far exceeded individual decision making skills. The authors measured the group added value (GAV) component, which was the percentage by which the group score was higher than the group's highest individual score. In addition, a synergy ratio was developed in this research, which attempted to measure how much a group added to their best member's contributions. The researchers found that the best members in a group rarely repeated their performance as a top scorer and became less important to group success as time went on and the group gained more experience. The results may relate better in management classes than quantitative methods classes where the material is somewhat cumulative.

This study sought to determine whether or not the same results could be obtained in an MBA Quantitative Research Methods class. The concept of group added value (GAV) is particularly important in this subject matter since MBA adult learners have, in many cases, been out of school for awhile. Most MBA students in this program work full time and there is a gap between their last college algebra or statistics class and the statistics class in their MBA program. In fact, many students delay taking the Quantitative Methods class until later in their MBA program out of fear or "math anxiety."

\section{METHODOLOGY}

Subjects were MBA students who were enrolled in a graduate level quantitative and research methods course. Students in this class take a series of five short, 25 multiple question tests called "minitests." These tests are not computational in nature; rather they assess knowledge of concepts, theory and the application of statistics as it related to research and making decisions in business situations. Their group experiences center on taking the same identical test as an individual. Both scores are weighted equally and are, in essence, averaged together when calculating their final grade.

Students are randomly assigned to groups at the beginning of the semester. They remain in these same groups throughout the duration of the course. There is some debate and research about group composition. Some research shows that group composition has an effect on the effectiveness of the group's ability to solve problems (Anderson, 2005). In an MBA class such as this one, group composition could be based on area of specialization, i.e. finance, marketing, management, human resources, international business, etc., or it could be based on job function. However, insuring that there is an equal distribution or these areas of expertise is a logistical nightmare and one can never be sure of getting equal representation in all groups.

Some research has shown that group composition, especially on the basis of expertise, really doesn't matter (Kelly, 2008; Muller, 1989). Given the body of research and the logistical difficulty of trying to create diverse groups based on job titles, this researcher decided to use a more "statistical" approach to group assignment, trusting random assignment to give groups a random chance to be diverse. Students simply count off randomly as the process progresses around the classroom, until everyone has a number. This represents the students' group number. Muller (1989) used the "people sequential heuristic" and found it to be effective in group formation. 
At the end of each class lecture, 15-20 minutes is usually reserved for students to work in their groups. Sometimes they use this time to study together, quizzing each other and helping group members prepare for the next week's minitest. Sometimes it is used for working together on computer assignments or the end of the semester research project that involves collecting and analyzing data from a problem or issue identified at their workplace. Since these adult learners work, have families, take other classes, and live in various parts of Southeastern Michigan, it is important to provide class time to meet in groups, rather than requiring out of class meetings. This helps the group develop and increases its success.

On days when minitests are administered, students take the test individually first, as all students do in all classes. When the last student finishes the test, the class breaks up into their pre-assigned groups and is handed the same identical test they just completed. They must come to a consensus on each and every question because only one answer per question is accepted. Sometimes they vote, sometimes compromises are made. Sometimes a student who thinks he or she is absolutely sure of the answer will try to convince the other students. Whatever process they use, a lot of discussions ensure and thus, a lot of explanations, clarifications, and learning takes place. No one student seems to always dominate. Rather, one student may excel in understanding Analysis of Variance (ANOVA), while another student may excel in understanding correlation and regression analysis. The most thrilling aspect of the group process is watching adult learners teach each other and learn from each other. As a result, their group scores are almost always higher than the highest individual score in that group on the same test. That means that the group scores exceed individual scores, thus supporting the GAV (group added value) that Watson, Michaelsen, and Sharp (1991) observed.

\section{RESULTS}

To support the hypothesis that group scores exceeded individual scores, date were collected over three semesters; worth of MBA Quantitative Methods sections. Individual scores were paired with their group's scores and a t-test was performed. The result of the t-test was as follows: individual means $=81.8344, \mathrm{sd}=11.21346, \mathrm{n}=$ 157. Group means $=94.3822, \mathrm{sd}=4.26605, \mathrm{n}=157, \mathrm{t}=-14.807, \mathrm{p}=.000$. There were 6 individuals who scored higher than the group score and 22 individuals scored as high as the group, out of 157 scores. All of the rest of the group scores were above the highest individual score. The gap between individual and group scores was sometimes as large as 50 points, where individuals scored $50 \%$ and the group scored $100 \%$.

\section{CONCLUSION}

Students in an MBA Quantitative Research Methods Class were exposed to group testing in an attempt to enhance and increase their understanding of difficult statistical concepts. Overall, it was evident from this research that students benefited greatly from the opportunity to take their tests in a group situation where the concepts could be talked through and analyzed by the group. Even students who had mastered the material well benefited from the group experience since only 6 individuals scored higher than their group scores and 22 students did as well as their group. In all of these cases, the individual scored in the 90 's range with many scoring $100 \%$, just as the group had done. In fact, most of the groups scored $88 \%$ and above, with groups frequently scoring $100 \%$. In a difficult subject such as MBA Quantitative Methods, that is not an easy accomplishment. This research demonstrates that truly "many heads are better than one." Future research will investigate and quantify the GAV score to demonstrate how much value is added to an individual's score in comparison to the group score.

\section{AUTHOR INFORMATION}

Marla G. Scafe, Ph.D., has been a faculty member at Walsh College for 26 years teaching Quantitative Methods and Research at the undergraduate, masters, and doctoral levels. She has also been a consultant-evaluator for the Higher Learning Commission of North Central Association for over 15 years. Her research interests center around the use of group testing with adult learners. She can be reached at mscafe@walshcollege.edu. 


\section{REFERENCES}

1. Anderson, Jonathan R. (2005). The relationship between student perceptions of team dynamics and simulation game outcomes: an individual level analysis. Journal of Education for Business. Washington: 81(2), 85-91.

2. Humphreys, P., Greenan, K., \& McIIveen, H. (1997). Developing work-based transferable skills in a university environment. Journal of European Industrial Training. 21(2), 63-69.

3. Huff, Lenard C., Cooper, Joanne, \& Jones, Wayne. (2002). The development and consequences of trust in student project groups. Journal of Marketing Education. Boulder: 24(1), 24-35.

4. Kelly, Phil. (2008). Achieving desirable group-work outcomes through the group allocation process. Team Performance Management. 14(1/2), 22-38.

5. Michaelsen, L. K., and Black, R. H. (1994). Building Learning Teams: The key to harnessing the power of small groups in higher education, in S. Kadel and J. Keekner, eds., Collaborative Learning: A Sourcebook for Higher Education., State College, Penn.: National Center for Teaching, Learning, and Assessment, 2, 65-81.

6. Michaelsen, L. K., Black, R. H., and Fink, L. D. (1996). What every faculty developer need to know about learning groups, in L. Richlin, ed., To improve the Academy: Resources for Faculty Instructional, and Organizational Development, Stillwater, OK.: New Forums Press Co., 31-58.

7. Michaelsen, L. K., Fink, L. D., and Knight, A. (1997). Designing Effective Group Activities: Lessons for Classroom Teaching and Faculty Development, in D. DeZure, ed., To Improve the Academy: Resources for Faculty, Instructional, and Organizational Development, Stillwater, OK.: New Forums Press Co., 373-397.

8. Michaelsen, L. K., Jones, C. F., and Watson, W. E. (1993). Beyond Groups and Cooperation: Building high-performance learning teams in D. L. Wright and J. P. Leende, eds., To Improve the Academy: Resources for Faculty, Instructional, and Organizational Development, Stillwater, OK.: New Forums Press Co., 1-5.

9. Michaelsen, L. K. (1997-98). Three keys to using learning groups effectively, Teaching Excellence: Toward the Best in the Academy, Ames, Iowa: POD Network, 9.

10. Michaelsen, L. K. (1999). Myths and methods in successful small group work, National Teaching and Learning Forum, 8, (6), 1-5.

11. Michaelsen, L. K., and Razook, N. M. (1999). Making learning groups effective, Selections, 16, (1), 28-35.

12. Muller, Thomas E. (Summer 1989). Assigning students to groups for class projects: an example, Decision Sciences, Atlanta: Vol. 20, (3), 623-635.

13. Watson, Warren E., and Michaelsen, Larry K. (Dec. 1988). Group interaction behaviors that affect group performances on an intellective task (cooperative task completion), Group and Organization Studies, 13, (4), 495-517.

14. Watson, Warren E., Michaelsen, Larry K., and Sharp, Walt. (Dec 1991). Member competence, group interaction, and group decision making: a longitudinal study, Journal of Applied Psychology, 76, (6), 803810.

15. Willcoxson, Lesley E. (Dec. 2006), "It's not fair!”: Assessing the dynamics and resourcing of teamwork, Journal of Management Education, 30, (6), 798-808. 